\title{
ANÁLISE DA VARIABILIDADE GENÉTICA DO ÉXON 10 DO GENE CFTR
}

\section{Genetic variability analisys of exon 10 of cftr gene}

\author{
Andrea Kuhnl ${ }^{1}$ \\ Fábio Rueda Faucz ${ }^{2}$ \\ Resumo
}

A Fibrose Cística (FC) é a doença hereditária autossô mica recessiva mais freqüente na população de origem caucasóide. Sua incidência varia de acordo com a população analisada, sendo em geral de 1:2.500 nascidos vivos com uma freqüência de portadores de 1:25. No Brasil, até o momento não foi realizado nenhum estudo amplo o suficiente sobre a incidência da fibrose cística, devido ao tamanho da população, ao fato de que em muitas localidades o diagnóstico ainda é deficitário, e de que existe uma heterogeneidade muito grande nessa população, o que indica que a incidência da doença provavelmente deve ser bastante distinta entre as regiões. 0 éxon 10 do gene CFTR foi analisado utilizando-se a técnica de PCR seguida da análise de conformação de polimorfismo de cadeia simples (SSCP) para a detecção de padrões anô malos de bandas, indicativos de variantes na seqüência de DNA, em 151 amostras de voluntários do Centro Universitário Positivo. 0 éxon 10 é o que apresenta o maior número de mutações identificadas no gene CFTR e éum excelente ponto de partida para avaliação da variabilidade populacional existente nesse gene. Foram identificadas bandas anô malas em 7,22\% dos cromossomos, sendo que, das variantes encontradas, 0,76\% correspondiam a mutação p.F508del, 4,18\% correspondiam a polimorfismos e 2,28\% correspondiam a outro tipo de mutação. Esse estudo pode facilitar o diagnóstico de FC e 0 screening de portadores nessa população, bem como fornecer subsídios para estudos relacionados a aspectos evolutivos do gene.

Palavras-chave: CFTR; E xon; Fibrose cística; Mutação

\section{Abstract}

The Cystic Fibrosis (FC) is the hereditary autossomal recessive disease more frequent at the population of origin Caucasian. Their incidence varies with the population analysed, being large of 1:2.500 live births and a carrier frequency of porters of 1:25. In Brazil, actually, was not realized neither wide study baggy the adequate upon the incidence of the cystic fibrosis, due to the size of the population, in most of the localities, the diagnostic is difficult, and there are a heterogeneity exceeding in that population, shows that the incidence of the disease probably must be enough distinct among the regions. The exon 10 of gene CFTR was analyzed making use of the technic of PCR follow by the analisys single-strand conformation polymorphism (SSCP) for the detection of anomalous standard of bands, indicatives of variants at the sequency of D NA, in 151 samples of volunteers of Centro Universitario Positivo. The exon 10 is that shows most of mutation identified at the gene CFTR and is a excellent starter for the avaliation of variability populational existent in this gene. It were identified anomalous bands in 12,58\% of the cromossoms, being that, of the variants found, 1,32\% have corresponded the mutation p.F508del, 4,18\% have corresponded the polymorphisms and $2,28 \%$ have corresponded the another type of mutations. This advisement makes easy the diagnostic of FC and the screening of porters in that population, and furnish subsidies for the studies relacionateds with aspects evolutives of the gene.

Keywords: CFTR; Exon; Fystic fibrosis; Mutation.

\footnotetext{
${ }^{1}$ CRYOGENE Criogenia Biológica Ltda. Curitiba PR, Brasil. e-mail:andreak@cryogene.com.br

${ }^{2}$ Laboratório de Genética Molecular, CCBS, Pontifícia Universidade Católica do Paraná PUCPR, Curitiba, Paraná, Brasil. Endereço para correspondência: Prof. Dr. Fábio Rueda Faucz. Laboratório de Genética Molecular, CCBS, Pontifícia Universidade Católica do Paraná (PUCPR). R. Imaculada Conceição 1155, Prado Velho, Curitiba PR, Brasil, CEP 80251-901. Fone: (41) 3271-1740. e-mail: fabiorf@ cryogene.com.br.
} 


\section{Introdução}

A fibrose cística (FC), também conhecida como mucoviscidose, é uma doença genética de herança autossômica recessiva de grande incidência na população caucasóide, porém muito rara nos asiáticos (EWGCFG, 1999). Esta doença caracterizase por apresentar manifestações que comprometem os sistemas respiratório, digestório e reprodutor. Trata-se de uma disfunção das glândulas de secreção exócrina, sendo as manifestações clínicas mais freqüentes a tosse crônica seguida de pneumonias, bem como a desnutrição protéico-calórica. Se as manifestações clínicas forem acompanhadas por níveis de cloreto no suor acima de $60 \mathrm{mEq} / \mathrm{l}$, isto é suficiente para 0 diagnóstico de FC, uma vez que em 1959 foi demonstrada a associação entre o elevado nível do íon cloreto no suor de pacientes com FC (GIBSON; COOK, 1959, de acordo com CARAKUSHANSKY, 2001).

A prevalência que ocorre na população caucasóide é de 1:2.500 nascidos vivos numa freqüência de portadores de 1:25 (BOAT; WELSH; BEAUDET, 1989). Nos Estados Unidos, a sobrevida média é de 40 anos, porém, no Brasil, encontra-se perto dos 9 anos (Nogueira, 2001), podendo chegar aos 15 anos (JAVO RSKI, 2001). Esta pouca sobrevida no Brasil está principalmente relacionada à falta de um diagnóstico precoce, que levaria a uma melhoria na qualidade de vida dos portadores por meio de tratamentos adequados.

Em 1989, o gene da FC foi mapeado no braço longo do cromossomo 7 (7q31). Este gene possui 250 kilobases (kb) e contém 27 éxons. Atéo momento já foi demonstrada a existência de 1007 mutações (CFGAC, 2002), sendo a de ocorrência mais comum a perda de 3 nucleotídeos na posição 508, ocasionando a falta do aminoácido fenilalanina na proteína reguladora da condutância transmembranar. Esta mutação é conhecida como p.F508del e a proteína é identificada como CFTR (CFGAC, 2002).

Descrita por Anderson (1938), a doença caracteriza-se pelo acometimento sistêmico de glândulas exócrinas, com alteração da qualidade das secreções respiratórias, digestórias e genitais, além do suor, levando à pneumopatia crônica, síndrome de $\mathrm{m}$ á-absorção e infertilidade. $\mathrm{O}$ ter mo mucoviscidose foi introduzido por Farber (1945), pois ressaltava o fato desta doença caracterizar-se pelo aspecto espesso e viscoso das secreções. Em 1946 sugeriu-se pela primeira vez 0 padrão de herança autossômico recessivo que se caracteriza por afetar os dois sexos, possuir uma incidência aumentada de consangüinidade parental, apresentar genitor es de afetados como portadores assintomáticos e os afetados geralmente nascem de genitores nãoafetados. Em setembro de 1989, o gene CFTR foi clonado, seqüenciado, e sua mutação mais freqüente, conhecida como p.F508del, identificada (RO MMENS et al., 1989; RIO RD AN et al., 1989).

A fibrose cística (FC) ou mucoviscidose éa doença hereditária autossômica recessiva letal mais freqüente na população de origem caucasóide, com uma incidência média de 1 em 2.500 nascidos vivos e uma freqüência de portadores de 1 em 25 (BOAT; WELSH; BEAUDET, 1989).

A incidência da FC é muito baixa nas populações não-caucasóides (indianos, árabes, asiáticos e entre judeus africanos), bem como entre os índios americanos, os negros africanos e americanos, e os orientais (TAUSSIG, 1984). Apesar de dados pouco precisos, calcula-se uma incidência de 1:17.000 nos negros norte-americanos, enquanto são poucos os casos descritos em negros na Á frica (McDOUGALL, 1962; OPENHEIMER; ESTERLY, 1968). Os dados sobre os povos orientais revelam uma incidência de 1:90.000 na população oriental do Hawai (Wright; Morton, 1968), de 1:100.000 na comunidade oriental da GrãBretanha e pouquíssimos casos descritos no Japão (WELSH et al., 1995). Esta incidência pode variar muito. Nos Estados Unidos e Europa é de 1:1.600 a 2.000 nascidos vivos. Já no Brasil, estados como 0 Paraná possuem uma incidência estimada de 1:6.800 nascidos vivos (RASKIN, 2002).

Pode-se verificar com estes dados que existe uma grande diferença nos erros 
genéticos dos portadores conforme seu local de origem e sua descendência. Apesar de sua freqüência relativamente alta, sóem 1985 é que foi demonstrada uma ligação entre a enzima paraxonase (PON) e a fibrose cística (EIBERG et al., 1985). Neste mesmo ano, foi detectada uma forte ligação genética entre a FC e um marcador polimórfico denominado D OCRI-917, que sódepois foi localizado no braço longo do cromossomo 7 (KNOWLTON et al., 1985). Foi a partir do conhecimento desta localização (7q31) que se partiu para a identificação do gene CFTR. Em 1989, o gene da FC foi isolado e localizado no cromossomo 7 humano e após uma análise da sucessão de cD NA, esta mostrou que o produto deste gene é uma proteína chamada CFTR, que consiste em 1480 aminoácidos com um peso molecular de $180 \mathrm{kD}$ (KNOWLTON et al., 1985).

A estrutura da proteína CFTR pode ser descrita como tendo início na porção $\mathrm{N}$ terminal, onde a proteína tem seis regiões transmembranares (TMD-1) seguido de um primeiro módulo de ligação de nucleot ídeos (NBD-1 ou NBF-1). Flanqueando este local, existe um módulo regulador $(\mathrm{R})$ que é rico em proteína quinase, este éseguido por um segundo jogo de seis regiões transmembranares (TMD-2) e um segundo módulo de ligação de nucleotídeos (NBD-2 ou NBF-2) (MORALES et al., 1999).

$\mathrm{Na}$ fibrose cística ocorrem vários tipos de mutações, desde pequenas deleções, mutações sem sentido ou de sentido trocado. As exceções são grandes deleções ou $r$ earranjos na regi ão codificadora (CFGAC, 2002). As mutações no gene da fibrose cística não são aleatórias, e são mais freqüentes na região codificadora do gene CFTR, sendo principalmente encontradas no éxon 10 (CFGAC, 2002).

0 éxon 10 é o que apresenta o maior número de alterações na seqüência de nucleotídeos, sendo que a maioria delas são mutações não-sinônimas, gerando alterações na proteína CFTR, incluindo a mutação mais freqüente existente no gene, que é a p.F508del. Se uma técnica rápida de screening fosse desenvolvida para a detecção de algumas das mutações mais freqüentes 0 diagnóstico de pacientes seria mais rápido e o prognóstico poderia ser melhorado, incluindose a qualidade de vida.

A correlação entre genótipo e fenótipo de portadores da fibrose cística pode variar sensivelmente devido à presença de diferentes combinações de mutações no locus do gene. Porém, édifícil estabelecer esta correlação, como mostram os itens abaixo:

- elevado número de mutações raras;

- diferenças no quadro clínico dos portadores; e

- pequeno número de homozigotos para a mesma mutação (RASKIN; FAUCZ, 2001).

Tendo em vista estes aspectos, podese inferir que conforme o tipo de mutação e 0 local onde esta se encontra é que serão detectados os aspectos ambientais pelos quais este portador poderá passar em sua vida. Ao se saber qual o real defeito do portador, pode-se prever a manifestação clínica que o portador terá. Atualmente, já se sabe que determinadas mutações no gene CFTR predispõem a quadros clínicos mais graves e outras a quadros clínicos mais leves. No Brasil, existem dois grandes problemas com relação aos pacientes de fibrose cística: 0 primeiro é a demora no diagnóstico, o que dificulta 0 tratamento e que seria facilitado se técnicas de screening fossem mais rápidas e menos custosas, sendo que, se em todos os indivíduos que tivessem algum sintoma de fibrose cística fosse feito um rápido screening, provavelmente uma porcentagem relativa destes játeriam algum indício de se são ou não afetados $\mathrm{FC}$, fazendo com que, em caso positivo, já fosse iniciado um tratamento mais específico; o segundo é que muitas vezes, não se sabem as mutações que determinados indivíduos afetados apresentam, o que impede um prognóstico futuro de como a doença vai se desenvolver e, conseqüentemente, de como este indivíduo deve ser tratado a fim de melhorar a sua qualidade vida.

As mutações no gene da proteína CFTR reduzem a permeabilidade ao cloreto (Cl-). Este defeito chamou a atenção à função do transporte de cloreto pela CFTR e que pode ser observado como segue nos modelos de membrana que descrevem 0 papel da liberação de ATP na interação com 
o cloreto e o CFTR (MORALES et al., 1999). A hipótese original de que o gene CFTR funcionaria como um regulador da condutância parece estar correta. Recentemente, Devidas e Guggino (1997) propuseram três possíveis modelos para explicar a liberação e a função de ATP. Primeiramente, tanto ATP como cloreto podem ser transportados pelo gene CFTR; em outro modelo, o ATP é liberado por um transportador de ATP que é regulado pelo CFTR sem interferir no transporte de cloreto; e por fim, vesículas de ATP fundem-se à membrana da proteína CFTR e liberam ATP e cloreto conforme o gradiente osmótico. Além de fazer o transporte de ATP e cloreto, o CFTR também conduz a um fenótipo de resistência a muitas drogas, devido à exclusão de algumas drogas terapêuticas (WEI et al., 1995; WEI et al., 1997). Com relação ao aparelho digestório, ocorre insuficiência pancreática devido à obstrução dos ductos excretores da glândula, ocasionando a síndrome de má-absorção, cirrose biliar, obstrução intestinal distal por estase fecal e refluxo gastroesofágico. Alguns pacientes com FC apresentam a primeira manifestação digestiva da doença logo após 0 nascimento. A doença pulmonar é caracterizada por infecção endobrônquica associada à doença pulmonar obstrutiva crônica (DPOC). No aparelho genital masculino observase a agenesia congênita de vasos deferentes (ACDV), já nas mulheres 0 muco cervical espesso e com características bioquímicas alteradas atua como "espermicida" resultando em infertilidade em ambos os casos. As manifestações otorrinolaringológicas mais freqüentes nas glândulas salivares são a secreção salivar espessa com dilatação e fibrose dos ductos glandulares. As principais causas de óbito entre pacientes portadores de FC são a insuficiência respiratória e a desnutrição resultante da síndrome de má-absorção, ocasionadas principalmente por um diagnóstico tardio.

O diagnóstico, na maioria dos casos, écaracterizado por achados pancreáticos ou pulmonares e por um nível elevado de cloreto no suor (acima de $60 \mathrm{mEq} / \mathrm{l}$ ). Porém, com a possibilidade do diagnóstico molecular, ficou claro que um número considerável de pacientes com FC possuem níveis intermediários de cloreto no suor (entre 40 e $60 \mathrm{mEq} / \mathrm{l}$ ) e alguns possuem níveis normais (HUFF; HUANG; AREY, 1979, de acordo com CARAKUSHANSKY, 2001; KOSZTOLANY; MALIK; RUTISHAUSER, 1996, de acordo com CARAKUSHANSKY, 2001).

No Brasil, o que irá permitir 0 avanço no tratamento da FC é a portaria assinada pelo Ministro da Saúde, José Serra, que torna o teste do pezinho obrigatório para FC, ocasionando um diagnóstico neo e pós-natal precoce para a partir do ano de 2002 (JAVORSKI, 2001). Esse teste visa a verificar a presença da enzima tripsina, que é produzida pelo pâncreas e que se encontra aumentada no sangue dos portadores da disfunção. 0 mesmo ministro instituiu o 5 de setembro como Dia Nacional de Conscientização e Divulgação da Fibrose Cística (JAVORSKI, 2001).

As formas de tratamento atuais visam a controlar as manifestações clínicas básicas da disfunção. A identificação do gene afetado oferece grande esperança para realização de interações farmacológicas, bem como a terapia gênica. $\mathrm{O}$ tratamento clínico do quadro otorrinolaringológico da FC consiste essencialmente de lavagem nasal para evitar a estase de secreções, bem como 0 uso de antibioticoterapia adequada. 0 tratamento cirúrgico envolve muitas controvérsias: primeiro pela pouca função pulmonar que é deteriorada ou destruída e que dificulta a utilização de anestésicos seguros; segundo, pela pouca idade de alguns pacientes; e finalmente pela diversidade de técnicas cirúrgicas pelas quais 0 paciente pode passar. A identificação do gene da FC permitiu que se compreendessem os mecanismos do transporte iônico e que se estudasse a proteína na sua forma normal e mutada, propiciando uma base molecular para um melhor tratamento dos pacientes (RASKIN; FAUCZ, 2001). A clonagem do gene CFTR e 0 desenvolvimento de modelos experimentais de $\mathrm{FC}$ em animais permitiram a obtenção de DNAase recombinante, antiproteases e terapia gênica para a FC.

A terapia gênica para portadores de FC baseia-se no conceito da substituição do 
gene afetado, no caso, o gene CFTR. Existem diversos obstáculos, como: a compreensão da regulação e expressão do gene, bem como o desenvolvimento de vetores e de métodos que introduzam a cópia de gene normal nas células doentes, tudo isto para que se alcance um resultado satisfatório com este tipo de tratamento. Têm sido pesquisados vírus respiratórios que poderiam conter 0 código genético correto da proteína para regulação da condutância iônica, atuando como vetores para a transmissão da informação à s células do epitélio respiratório (WILMOTT; FIEDLER, 1994). Atualmente, já existem pesquisas para que o vírus usado como vetor, infecte diretamente as células pulmonares atingidas pela disfunção (LIU et al., 2002).

Recentemente, com os avanços no tratamento da FC, por meio da reposição de enzimas digestivas, fisioterapia respiratória, antibioticoterapia e a possibilidade de transplantes de pulmão, a morbidade dos pacientes tem sido reduzida, com melhor qualidade e expectativa de vida para os portadores da patologia.

Existem hipóteses para a elevada freqüência das mutaçõ es da fibrose cística na população caucasóide, entre elas:

- heterogeneidade genética;

- taxa elevada de mutação, (freqüência com a qual genes de efeito deletério são introduzidos na população em cada geração);

- deriva gênica, (variação aleatória das freqüências gênicas ao longo das gerações. Tanto pode haver a eliminação quanto a fixação de um ou mais genes, independentemente do valor adaptativo que esses genes conferem);

- vantagem seletiva para os heterozigotos, (neste estado, a resistência é aumentada para doenças infecciosas mantendo alelos mutantes de CFTR em níveis altos em populações selecionadas (PIER et al., 1998).

Dessas, a mais aceita é a possibilidade de uma vantagem seletiva para os portadores, em razão de certos fatores favoráveis tanto na reprodução quanto na sobrevivência contra os mecanismos seletivos, atuais ou passados (KNUDSON; WAYNE; HALLETT, 1967, de acordo com CARAKUSHANSKY, 2001; CASSANO, 1985, de acordo com CARAKUSHANSKY, 2001; LEWIS, 1995, de acordo com CARAKUSHANSKY, 2001; BERTRANPETIT; CALAFELL, 1996; JOSEFSON，1998, de acordo com CARAKUSHANSKY , 2001; PIER et al., 1998; GUGGINO, 1999, de acordo com CARAKUSHANSKY, 2001).

Neste artigo é apresentada a análise da variabilidade genética do éxon 10 do gene CFTR, estabelecendo-se um método de análise mais fácil, eficiente e com baixo custo para a identificação de portadores de fibrose cística, por meio da otimização da técnica de coleta da amostra em papel filtro, visando a avaliar a freqüência de alterações na seqüência de nucleotídeos do éxon 10 e diferenciando as mutações sinônimas e nãosinônimas presentes no referido éxon.

\section{Metodologia}

A amostra foi delimitada na população do campus do Centro Universitário Positivo UNICENP -, Curitiba, Paraná, constituída de alunos, professores e funcionários voluntários, sendo o total coletado de 151 amostras.

Coleta da Amostra: para a coleta da amostra, foi realizada uma breve explicação sobre 0 trabalho proposto, conversando-se com os voluntários. Após isso, o voluntário lia e, se estivesse de acordo, assinava 0 consentimento informado. Os responsáveis pela coleta da amostra usavam luvas descartáveis para que se evitasse ao máximo qualquer tipo de contaminação, principalmente de DNA oriundo de outra fonte que não a do voluntário. A amostra, então, era constituída por uma gota de sangue, que era coletada por meio de uma lanceta do kit próprio denominado Soft Clix ll sistema de punção da empresa Roche.

0 voluntário escolhia o dedo que era limpo de forma asséptica com álcool 70\% onde extraía-se a gota de sangue. Essa era imediatamente pingada em papel filtro com a identificação do voluntário, após estar seca era conservada em temperatura ambiente 
junto ao consentimento informado da pesquisa.

0 material genético foi então analisado por técnicas de PCR, eletroforese para controle de amplificado e SSCP.

O risco de contaminação da amostra épraticamente nulo, bem como o custo e 0 tempo para se desenvolver a técnica são reduzidos.

Reação em Cadeia da Polimerase PCR: no presente estudo a PCR foi realizada em um volume final de 50?L, contendo dNTPs $(0,2 \mathrm{mM}), \mathrm{MgCl} 2(2 \mathrm{mM})$, primers (50pmol/ ?l de cada um deltaF508 1 e deltaF508 2), PCR Buffer (1X) e papel filtro contendo amostra de sangue (quadrado de aproximadamente $1 \mathrm{~mm} 2$ ). Depois de 3 ciclos de 96 ? $\mathrm{C}$ por 3 minutos e 4 ? $\mathrm{C}$ por 3 minutos (para liberação das moléculas de DNA das células presas no papel filtro), a ciclagem foi interrompida em 80?C para a adição da Taq D NA-polimerase

$(1,5 \mathrm{U})$. A PCR foi realizada em 3 conjuntos de temperaturas: 19) 5 ciclos de 92?C (40"), 56?C (30") e 72?C (45"); 2) 15 ciclos de 92?C (30"), 54?C (30") e 72?C (45"); 3ㅇ) 20 ciclos de 92?C (15"), 52?C (15") e 72?C (20"), perfazendo em total de 40 ciclos, seguidos por uma extensão final de 72?C (10').

Eletroforese para Controle de Amplificado: Após a amplificação era realizada uma eletroforese em gel de agarose para controle de amplificado. Usou-se 0 gel de agarose com concentração de $1 \%$ por meio do uso de $0,3 \mathrm{~g}$ de agarose e $30 \mathrm{~mL}$ de tampão TBE 1X. A corrida eletro forética era realizada em um tempo de 30 minutos com voltagem de $100 \mathrm{~V}$, e posterior a ela era realizada a coloração com brometo de etídio por 30 minutos para a visualização das bandas.

Análise de Conformação de Polimorfismo em Cadeia Simples SSCP: quando as amostras tinham sua amplificação confirmada através do gel de agarose, realizava-se então a técnica de SSCP que foi realizada em um gel de poliacrilamida $10 \%$ (29:1) com adição de glicerol a 5\%. A polimerização do gel era realizada a 23?C e a corrida a 19?C. A desnaturação da amostra era realizada a 92?C por 5 minutos. 0 volume final de aplicação era de 11?L, sendo 5 ?L de amostra e 6? $\mathrm{L}$ de corante que foi formulado a partir de 4,75mL de formamida 95\% como agente desnaturante; 0,0125g de xileno cianol $0,25 \%$; $0,0125 \mathrm{~g}$ de azul de bromofenol 0,25\%; 125?L de EDTA $(0,4 \mathrm{M})$ $10 \mathrm{mM} ; 16,7$ ? L de $\mathrm{NaOH}(0,3 \mathrm{M}) 10 \mathrm{mM}$ e 108,3?L de água bidestilada. Os géis foram corados com nitrato de prata $0,2 \%$ baseados na técnica descrita por Schiff e Freedberg (1989).

Após terminar 0 processo de coloração, o gel era então acondicionado em uma folha de papel celofane como se fosse um sanduíche. Posteriormente 0 gel era xerocado ou escaneado para então ser realizada a padronização das bandas encontradas.

Análise Estatística: foi realizada a análise da freqüência alélica para se verificar as repetições encontradas na população estudada por meio da fórmula: $\mathrm{f}(\mathrm{a})=\mathrm{n} / \mathrm{N}$.

Onde: f(a) representa a freqüência alélica da repetição, n é o número de alelos da repetição que foram encontrados na população e N é o número total de alelos da população em estudo.

\section{Resultados}

Os resultados desse trabalho foram obtidos por meio da realização de duas etapas, conforme segue:

\section{Análise das amostras coletadas:}

Nessa etapa foi realizada a análise das amostras coletadas em papel filtro por meio de 6 PCRs e 8 géis para SSCP, os resultados encontrados seguem conforme a tabela 1.

Tabela 1 Total de análises realizadas

\begin{tabular}{ll}
\hline AMOSTRAS & RESULTAD O S \\
\hline 40 & Sem resultado identificado \\
33 & n/ outra \\
4 & n/d \\
74 & $\mathrm{n} / \mathrm{n}$ \\
151 & TOTAL
\end{tabular}

NOTA: $\mathrm{n} /$ outra $=$ normal/ outra alteração; $\mathrm{n} / \mathrm{d}=$ normal/ deleção; $\mathrm{n} / \mathrm{n}=$ normal/ normal.

FONTE: O Autor. 


\section{Confimação dos resultados obtidos:}

Essa etapa foi composta pela realização de dois géis para SSCP, onde foram analisadas as 37 amostras que apresentaram algum tipo de padrão anômalo, onde se obtiveram os resultados demonstrados na tabela 2 .

Tabela 2 Padrões confirmados

\begin{tabular}{lll}
\hline $\begin{array}{l}\text { AMOST } \\
\text { RAS }\end{array}$ & RESULTADO & $\begin{array}{l}\text { CODIGO DA } \\
\text { AMOST RA }\end{array}$ \\
\hline 4 & Polimorfismo A & 033, 047, 082, \\
& & 151 \\
3 & Polimorfismo B & $001,036,037$ \\
2 & Polimorfismo C & 056,058 \\
2 & Polimorfismo D & 083,087 \\
6 & Padrões & de \\
& alterações & $026,050,089,090$ \\
2 & $\mathrm{n} / \mathrm{d}$ & 027,055 \\
18 & $\mathrm{n} / \mathrm{n}$ & Todas as \\
& & demais \\
& & amostras \\
\hline
\end{tabular}

NOTA: $\mathrm{n} / \mathrm{d}$

FONTE: O Autor.

As amostras que não tiveram seu resultado identificado foram novamente submetidas a uma PCR e a dois géis para SSCP, onde 20 amostras foram confirmadas como $n / n$ e as demais (20) não puderam ser identificadas quanto ao padrão esperado para FC.

Dentro do total observado, encontraram-se quatro padrões para polimorfismos e seis padrões para alterações com 10 alelos envolvidos. Para se chegar a esses resultados, desconsiderou-se os portadores da alteração $\mathrm{n} / \mathrm{d}$, tendo em vista que esse trabalho foi proposto na análise das demais alterações encontradas éxon 10.

Baseado nos resultados obtidos partiuse para 0 cálculo da freqüência alélica de cada um dos polimorfismos e alterações encontradas, conforme mostra a tabela 3.

Tabela 3 Freqüências alélicas encontradas

\begin{tabular}{lc}
\hline ALELOS & FREQÜÊECIA \\
\hline Polimorfismo A & $1,52 \%$ \\
Polimorfismo B & $1,14 \%$ \\
Polimorfismo C & $0,76 \%$ \\
Polimorfismo D & $0,76 \%$ \\
Alteração A & $0,38 \%$ \\
Alteração B & $0,38 \%$ \\
Alteração C & $0,38 \%$ \\
Alteração D & $0,38 \%$ \\
Alteração E & $0,38 \%$ \\
Alteração F & $0,38 \%$ \\
n/ d & $0,76 \%$ \\
\hline NOTA: n/ d = normal/ deleção. &
\end{tabular}

FONTE: O Autor.

\section{Discussão}

D esde a identificação do gene responsável pela fibrose cística, já foi demonstrada a existência de 1007 mutações detectadas no gene CFTR das quais 57 encontram-se no éxon 10, desconsiderandose a mutação p.F508del (CFGAC, 2002).

Com base nos resultados obtidos e que foram demonstrados na tabela 3, partiuse para a avaliação da freqüência alélica dos indivíduos com fenótipo dominante que são heterozigotos.

De todas as amostras analisadas, 20 delas não puderam ter seu resultado identificado quanto ao padrão esperado para o gene CFTR da fibrose cística. Essa não identificação pode ter ocorrido pelo fato de que o DNA usado na metodologia de papel filtro precisa ser muito bem separado para que sua amplificação ocorra de maneira precisa para que então se possa verificar com precisão o resultado.

Com base no resultado encontrado na avaliação da freqüência alélica, pode-se avaliar a freq üência de alterações na seq üência de nucleotídeos do éxon 10. Pode-se ainda diferenciar as alterações encontradas em sinônimas e nãosinônimas de acordo com:

-SINôNIMAS: foram os polimorfismos encontrados e que foram assim definidos por terem sido encontradas em mais de um indivíduo;

- NÃO-SINÔNIMAS: foram as alterações propriamente ditas, pois estas 
foram encontradas em apenas um indivíduo de cada vez.

De acordo com os resultados evidenciados na figura 1, sabe-se que os polimorfismos encontrados não acarretam alterações funcionais em seus portadores, visto que a grande diferença nos erros genéticos dos portadores ocorre conforme seu local de origem e sua descendência. Jádas seis alterações encontradas, não se tem certeza se essas são polimorfismos ou se são realmente alterações (mutações propriamente ditas), para isso seria necess ária a realização do seqüenciamento do DNA em questão. Porém, como foram encontrados apenas dois portadores da mutação mais freqüente para 0 gene da $\mathrm{FC}$, a mutação p.F508del, pode-se inferir que das alterações encontradas essas sejam apenas polimorfismo devido a suas baixas freqüências alélicas.

Conforme todos os resultados obtidos e a metodologia de papel filtro utilizada na realização desse trabalho, podese concluir que essa metodologia mostrou-se de grande eficiência para 0 scr eening populacional, uma vez que se podem verificar as freqüências alélicas de cada alteração na população estudada. Jápara um scr eening diagnóstico, essa metodologia não foi tão eficiente, já que para se conhecer 0 tipo de alteração encontrada seria necessária a realização da técnica de seqüenciamento, 0 que dificultaria 0 diagnóstico pelo encarecimento da técnica.

\section{Referências}

ANDERSON, D.H. Cystic fibrosis of the pancreas and its relation to celiac disease: A clinical and pathological study. Am J Dis Child, 56:344-399,1938.

BERTRANPETIT, J.; CALAFELL, F. G enetic and geographical variability in cystic fibr osis: evolutionary considerations. Ciba Found Symp, 197:97-114, 1996.

BOAT, T.F.; WELSH, M.J.; BEAUDET, A.L. Cystic Fibrosis. In: SCRIVER, C.R.; BEAUDET, A.L.; SLY, W.S.; VALLE, D. The metabolic basis of inhenited disease,
6. ed. New Y ork: Mc Graw-Hill, 1989. Vol. 2.

CARAKUSHANSKY, G. Doenças Genéticas em Pediatria. Rio de Janeiro: Guanabara-K oogan, 2001.

CASSANO, W.F. Cystic fibrosis and the plague. Med Hypoth, 18(1):51-52, 1985.

\section{CFGAC. Cystic fibrosis mutation data base. Disponível em: <http:/ / www.genet.sickkids.on.ca/ cftr/ > Acesso em: 2001 e 2002.}

DEVIDAS, S.; GUGGINO, W.B. The cystic fibrosis transmembrane conductance regulator and ATP. Curr Opin Cell Biol, 9(4):547-552, 1997.

EIBERG, H.; MOHR, J.; SCHMIEGELOW, K.; NIELSEN, L.S.; WILLIAMSO N, R. Linkage relationships of paroxonase (PON) with other markers: indication of PON cystic fibrosis synteny. Clin Genet, 28(4):265-271, 1985.

EWGCFG. Gradient distribution in Europe of the major $\mathrm{CF}$ mutation and of its associated haplotype. Hum Genet, 85(4):436-441, 1999.

FARAH, S.B. DNA segredos e mistérios. São Paulo: SARVIER, 1997.

FARBER, S. Some organic digestive disturbances in early life. J Michigan Med Soc, 44:587, 1945.

GIBSON, L.E.; COOK, R.E. A test for concentration of electrolytes in sweat in cystic fibrosis of Pancreas utilizing Pilocarpine by iontoforesis. Pediatrics, 23:545-549, 1959.

GUGGINO, S.E. Evolution of the delta F508 CFTR mutation. Trends Microbiol, 7(2):55-58, 1999.

HUFF, D.S.; HUANG, N.N.; AREY, J.B. Atypic cystic fibrosis of the pancreas with normal levels of sweat chloride and minimal 
pancreatic lesions. J. Pediatr, 94(2):237-239, 1979.

JAVORSKI, J. Fibrose cística ganha dia de luta. Gazeta do Povo On Line, 2001.

JOSEFSON, D. CF gene may protect against typhoid fever. BMJ, 316(7143):1481, 1998.

KNOWLTON, R.G.; COHENHAGUENAUER, O ; VAN CONG, N.; FRÉ ZAL, J.; BROWN, V.A.; BARKER, D .; BRAMAN, J.C.; SCHUMM, J.W.; TSUI, L.C.; BUCHWALD, M. A polymorphic DNA marker linked to cystic fibrosis is located on chromosome 7. Nature, 318(6044):380-382, 1985.

KNUDSON， A.G.Jr.; WAYNE， L.; HALLETT, W.Y. On the selective advantage of cystic fibrosis heterozygotes. Am J H um Genet, 19(3):388-392,1967.

KOSZTOLANYI， G.; MALIK， N.; RUTISHAUSER, M. Mild CF in a delta F 508? R347H compound heterozygote womam: does the manifestation of this genotype differ in the two sexes? Clin Genet, 49(2):103-105, 1996.

LEWIS, E. Cólera e fibrose cística um novo exemplo de seleção natural de heterozigotos? Porto Alegre, 1995. f. Dissertação (Mestrado em Bioquímica) PósGraduação em Ciências Biológicas Bioquímica, Universidade Federal do Rio Grande do Sul.

LIU, X.; JIANG, Q .; MANSFIELD, S.G .; PUTTARAJU, M.; ZHANG, Y.; ZHOU, W.; COHN, J.A.; GARCIABLANCO, M.A.; MITCHELL, L.G.; ENGELHARDT, J.F. Partial correction of endogenous F508 in human cystic fibrosis airway epithelia by spliceosomemediated RNA trans-splicing. N ature Biotechnol, 20:47-52, 2002.

McD OUGALL, L.G. Fibrocystic disease of the pancreas in African children. Lancet, 1:409-410, 1962.
MORALES, M.M.; CAPELLA, M.A.M.; LOPES, A.G. Struture and funtion of the cystic fibrosis transmembrane conductance regulator. Braz J Med Biol Res, 32(8):10211028, 1999.

NOGUEIRA, D. Mutações brasileiras da fibrose cística. J Brasil, 2001.

OPENHEIMER, E.H.; ESTERLY, J.R. Cystic fibrosis in non-Caucasian patients. Pediat, 42:547-548, 1968.

PIER, G.B.; GROUT, M.; ZAIDI, T.; MELULENI, G.; MUESCHENBORN, S.S.; BANTING， G.; RATCLIFF， R.; EVANS, M.J.; COLLEDGE, W.H. Salmonella typhi uses CFTR to enter intestinal epithelial cells. Nature, 393(6680):79-82, 1998.

RASKIN, S. Fibrose cística: uma patologia em evidência. Disponível em: <http:/ / www.genetika.com.br/ fibrosec.htm $>$ Acesso em: 2002.

RASKIN, S.; FAUCZ, F.R. Aspectos genéticos da fibrose cística. In: CARAKUSHANSKY， G. Doenças Genéticas em Pediatria. Rio de Janeiro: Guanabara-Koo gan, p. 227-241, 2001.

RIORDAN， J.R.; ROMMENS, J.M.; KEREM, B.; ALON, N.; ROZMAHEL, R.; GRZELCZAK, Z.; ZIELENSKI, J.; LOK, S.; PLAVSIC, N.; CHOU, J.L.; et al. Identification of the cystic fibrosis gene: cloning and characterization of complementary DNA. Science, 245(4922):1066-1073, 1989.

ROMMENS, J.M.; IANNUZZI, M.C.; KEREM, B.; DRUMM, M.L.; MELMER, G.; DEAN, M.; ROZMAHEL, R.; COLE, J.L.; KENNEDY, D.; HIDAKA, N.; et al. Identification of the cystic fibrosis gene: chromosome walking and jumping. Science, 245(4922):1059-1065, 1989.

SCHIFF, T.A.; FREEDBERG， I.M. Ultrasensitive polychromatic silver staining of sodium dodecyl sulfate-polyacrylamide gels with the gelcode system using the 
phastsystem development unit.

Electrophoresis, 10(7):535-6, 1989.

TAUSSIG, L.M. Cystic fibrosis. An Overview. In: TAUSSIG, L.M. Cystic fibrosis. New York: ThiemeStratton, 1984. p. 1-9.

WEI, L.Y.; STUTTS, M.J.; HOFFMAN, M.M.; ROEPE, P.D. Overexpr ession of the cystic fibrosis transmembrane conductance regulator in NIH 3T3 cells lowers membrane potential and intracellular $\mathrm{pH}$ and confers a multidrugs resistance phenotype. Biophys J, 69(3):883-895, 1995.

WEI, L.Y.; HOFFMAN , M.M.; ROEPE, P.D. Altered pHi regulation in 3T3/ CFTR clones and their chemotherapeutic drugselected derivatives. Am J Physiol, 272(5 Pt 1): C1642-C1653, 1997.

WELSH, M.J.; TSUI, L.C.; BOAT, T.F.; e BEAUDET, A.L. Cystic fibrosis. In: SCRIVER, C.R.; BEAUDET, A.L.; SLY, W.S. e VALLE, D. The metabolic and molecular bases of inherited disease. 7 . ed. New York: McG raw-Hill, 3:3799-3876, 1995.

WILMOTT, R.W.; FIED LER, M.A. Recent advances in the treatment of cystic fibrosis. Pediatr Clin N Am, 41(3):431-451, 1994.

WRIGHT, S.W.; MORTON, N.E. Genetic studies on cystic fibrosis in Hawai. Am J Hum Genet, 20:157- 169, 1968.

Recebido em 14/ 10/ 2004; aceito em 13/ 12/ 2004

Received in 10/ 14/ 2005; accepted in 12/ 13/ 2004 